\title{
Groundwater pollution and human health risk based on Monte Carlo simulation in a typical mining area in Northern Anhui Province, China
}

\author{
Huili Qiu ${ }^{1,2} \cdot$ Herong Gui ${ }^{1}\left[\right.$ Pei Fang ${ }^{3} \cdot{\text { Guangping } \mathrm{Li}^{3}}^{3}$
}

Received: 13 August 2020/Revised: 18 March 2021 / Accepted: 11 June 2021 / Published online: 16 July 2021

(C) The Author(s) 2021

\begin{abstract}
The main objective of this study was to evaluate eight kinds of trace element pollutants in groundwater from a typical coal mine area, and carry out a corresponding health risk assessment for the local populace. To do this, 34 shallow groundwater (SG) samples and 18 mid-layer groundwater (MG) samples were collected from the Sulin mining area. To minimize the uncertainties in the health risk assessment, this paper relied on Monte Carlo simulations and sensitivity analysis. The results revealed that $\mathrm{Sr}$ and $\mathrm{Mn}$ contents exceeded their corresponding WHO (Guidelines for drinking water quality, 4th edn. Geneva, 2011) guidelines and Chinese groundwater standards (GB/T14848-2017), while the other analyzed trace elements remain below those threshold values. The calculated hazard quotient and hazard index values for adults from ingestion exposure to SG and MG were well below the threshold limit of 1. Probabilistic simulations further show that the total cancer risk value above the limit of $1 \times 10^{-6}$ is $0 \%$ for SG and $29.39 \%$ for MG. Sensitivity analysis identified the $\mathrm{Sr}$ and $\mathrm{Cr}$ contents as the most relevant element variables affecting the probabilistic non-carcinogenic and carcinogenic risk values in the model, respectively.
\end{abstract}

Keywords Health risk assessment $\cdot$ Trace elements $\cdot$ Monte Carlo simulation $\cdot$ Sensitivity analysis $\cdot$ Mining area

\section{Introduction}

Water is the source of all life and an indispensable substance for living organisms (Jiang et al. 2020). Groundwater is an important source of water for agricultural production and domestic uses, among others (Adimalla and $\mathrm{Wu}$ 2019), especially in areas lacking surface water. It is well known that groundwater is a vulnerable nature resource, and the mounting pressure on groundwater

Herong Gui

guiherong@163.com

1 Engineering Research Center of Coal Mine Exploration of Anhui Province (Suzhou University, Suzhou 234000, Anhui, China

2 School of Information Engineering, Suzhou University, Suzhou 234000, Anhui, China

3 Qianyingzi Coalmine of Wanbei Coal-Electricity Group Co. Ltd., Suzhou 234000, Anhui, China resources may result in a shortage of water resources coupled with their chemical contamination (Nurtazin et al. 2020; Chen et al. 2021). Once groundwater is contaminated, it severely disrupts the aquatic ecosystem's structure and functioning, such that reverting to its original state takes very a long time. Moreover, the consumption of groundwater with excess amount of contaminants may endanger human health. Trace elements are viewed as priority contaminants, because their presence in excess concentrations may threaten human health and disrupt ecological security (Hossain and Patra 2020). Therefore, a better understanding of the degree of water contamination and potential health risk via exposure to these trace elements is necessary.

Health risk assessment is a method that links health to the degree of water pollution (Kaur et al. 2019). It can be used quantitatively describe health risks; however, most studies have evaluated health risks by using the US-EPA model (Bodrud-Doza et al. 2019; Cai et al. 2019; Xiao 
et al. 2019; Zhang et al. 2018), which relies on a single point value of each trace element to estimate the risk hazard. The results obtained using this method may overestimate or underestimate the true risks, and may foster uncertainty in the model results. Because of the complexities and uncertainties of the water environment, the process and results of health risk assessment are best characterized by fuzziness. Therefore, many scholars have introduced uncertainty theory into groundwater health risk assessments to address the uncertainty in their model results, for which probabilistic approach to evaluate health risks has recently become a popular trend (Yang et al. 2018; Qiu and Gui 2019; Zhang et al. 2017). Aided by Monte Carlo simulations, a probabilistic risk analysis uses the probability distribution of an input variable to evaluate the probability distribution of its output risk. Hence, this approach is likely to yield higher accuracy in the health risk assessment model's results, which assesses the ranges of possible risk values, assigning a specific probability to each (Saha et al. 2017).

In the present work, the study area is a major mining area in the Huaibei coal basin. It is rich in coal, with 19 active coal mines, some of which have a long mining history. In recent years, investigations by researchers suggest that certain coal mines are facing a water shortage and chemical contamination. The fly ash and coal cinder from coal-mining activities are laden with toxic trace elements and easily enter groundwater via runoff and infiltration (as well as other forces) during coal washing and coal cinder stacking-finally causing surface water pollution and shallow groundwater pollution (Wang et al. 2019; Long and Luo 2020; Hu et al. 2021). Moreover, excessive midlayer groundwater exploitation causes a decline in water levels as well as an increase in the water level difference between the shallow and mid-layer groundwater bodies. Consequently, leakage recharge occurs where the first aquifuge is thin, that is from shallow groundwater (SG) to mid-layer groundwater (MG), and then toxic trace elements produced by surface coal mining activities enter MG, exacerbating its pollution. Taking that into consideration, this study systematically collected SG and MG samples and measured eight trace elements in them. The present research sought to investigate the degree of SG and MG contamination, and find out which pollutants were affecting the groundwater quality. In addition, this study introduced Monte Carlo simulations into the US-EPA health risk assessment model, so that its results could attain greater accuracy. The findings of this research work are expected to provide a scientific basis for strengthening the environmental protection of drinking water.

\section{Material and methods}

\subsection{Study area and its geological background}

The Sulin mining area is located in the Northern Anhui Province, China, lying between $33^{\circ} 20^{\prime}-33^{\circ} 42^{\prime} \mathrm{N}$ and $116^{\circ}$ $15^{\prime}-117^{\circ} 12^{\prime} \mathrm{E}$ (Fig. 1). The study area has a relatively simple terrain, and is home to 19 coal mines. This region under investigation has mainly a semi-humid monsoon type of climate. The mean temperature and rainfall are $14.6{ }^{\circ} \mathrm{C}$ and $867 \mathrm{~mm}$, respectively. The Huaihe River and Tuohe River are natural surface water bodies that flow through the study area, being medium and small seasonal rivers (Yu et al. 2020a, b).

The study area is covered by a Quaternary thick, loose layer of Cenozoic. According to the regional stratigraphic distribution, lithologic characteristics, and the spatial distribution of the aquifer, the regional aquifer groups can be divided into those of loose rock pore, conglomerate karst, clastic rock and igneous rock fracture, and limestone karst fissure. Loose rock pore aquifer groups mainly consist of Quaternary and Neogene sand and gravel layers, which are mixed with a clay layer. The Cenozoic group contains four aquifers, namely, the first, second, third, and fourth aquifers (Qiu et al. 2019). The SG is derived from the first aquifer having a mean thickness of $30 \mathrm{~m}$, while MG comes from the second and third aquifers. Collectively, they are the main water sources of industrial, agricultural, and domestic water in the mining area.

\subsection{Field sampling}

A total of 52 fresh groundwater samples (including 34 SG and $18 \mathrm{MG}$ samples) were taken in 2.5 -L prewashed sterile polyethylene bottles, from across the entire coal-mining district in July and August 2017. The SG samples were drawn from domestic wells (depth to water levels were less than $30 \mathrm{~m}$ ), using a systematic random sampling technique, while MG samples were drawn from water source wells (depth to water levels were $80-130 \mathrm{~m}$ ). The specific sampling locations appear in Fig. 1. To minimize pollution, prior to pouring the water samples into the bottles, each well was pumped for 10-15 min, and then the bottles were rinsed with sample water. A portable GPS device was used to record the coordinates of each sampling site. During their collection, all the water samples were acidified, using technical grade concentrated nitric acid at $\mathrm{pH}<2$. The sampling bottles were sealed, labeled, and taken to the laboratory for further analysis. 


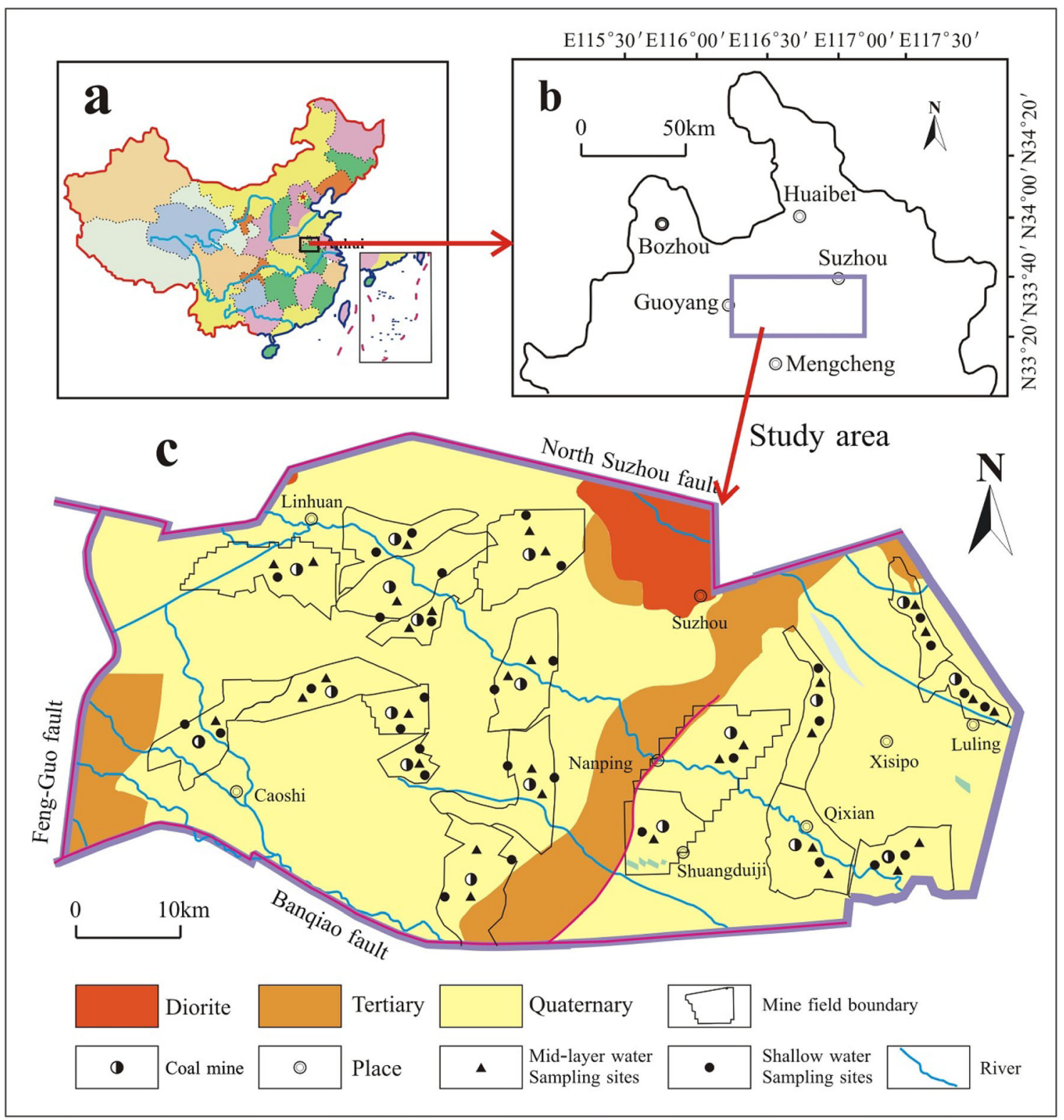

Fig. 1 Geographical map of the study area in China (a, b) and water sampling locations (c)

\subsection{Chemical analysis}

Trace elements' concentrations were tested by an inductively coupled plasma-mass spectrometry (ICP-MS) (Agilent $7500 \mathrm{cx})$. The concentrations of eight trace elements$\mathrm{Cr}, \mathrm{Mn}, \mathrm{Ni}, \mathrm{Cu}, \mathrm{Zn}, \mathrm{Sr}, \mathrm{Cd}$, and $\mathrm{Pb}$ - were higher than the detection limit, while other trace elements (e.g., As and $\mathrm{Hg}$ ) contents were lower than the detection limit. At the time of groundwater samples' testing, the calibration of the instruments (for example procedural blanks, reagent blanks, and detection limits) were designed to ensure robust quality control. Recoveries of the measured trace elements were $95.2 \%-102.5 \%$ for spiked blanks, and $97.5 \%-101.5 \%$ for spiked samples with $\pm 5 \%$ standard deviation. All the samples were tested thrice, and their averaged values regarded as the final experimental data for each target trace element. The relative percentage differences of the experimental data remained below $5 \%$.

\subsection{Human health risk assessment methods}

\subsubsection{Exposure assessment}

The chemical constituents in contaminated groundwater may pose a detrimental health impact to humans via ingestion, inhalation and dermal absorption (Al osman et al. 2019). For trace elements in a groundwater environment, all other exposure routes can be ignored when 
compared with oral ingestion. The average daily dose (ADD) $(\mu \mathrm{g} /(\mathrm{kg} \mathrm{d}))$ through oral ingestion for adults was calculated using Eq. (1).

$\mathrm{ADD}=\frac{C_{\text {water }} \times \mathrm{IR} \times \mathrm{EF} \times \mathrm{ED}}{\mathrm{BW} \times \mathrm{AT}}$

Its model parameters are given in Table 1.

\subsubsection{Non-carcinogenic risk assessment}

The non-cancer risks in a specific pathway posed by each detected trace element can be conveyed as a hazard quotient (HQ). The HQ was calculated as:

$\mathrm{HQ}=\frac{\mathrm{ADD}}{\mathrm{RfD}}$

where, RfD is the reference dose $(\mu \mathrm{g} /(\mathrm{kg} \mathrm{d}))$. For each trace element, its RfD values (Table 2) were gathered from the US-EPA's integrated risk information system (IRIS) database.

To evaluate the total non-cancer hazards from oral ingestion, we introduced the hazard index, which is sum of HQs from all eight detected trace elements.

$\mathrm{HI}=\sum_{i=1}^{n} \mathrm{HQ}_{i}$

An HI of $<1$ indicates an acceptable level of risk.

\subsubsection{Carcinogenic risk assessment}

Carcinogenic risks (CR) caused by carcinogens via oral ingestion exposure pathway were quantified using Eq. (4).

$\mathrm{CR}=\mathrm{ADD} \times \mathrm{SF}$

where, SF denotes the carcinogenic slope factor of a given pollutant, expressed as $(\mathrm{mg} /(\mathrm{kg} \mathrm{d}))$. The values used for SF are in Table 2. If several carcinogens are present in the groundwater environment at the same time, the carcinogenic risks caused by all carcinogens are summed.

Table 1 Model parameters and their values

\begin{tabular}{lll}
\hline Input parameter & Symbol & Value \\
\hline Exposure duration (year) & $\mathrm{ED}$ & 30 \\
Exposure frequency (d/yr) & $\mathrm{EF}$ & 350 \\
Ingestion rate $(\mathrm{L} / \mathrm{d})$ & $\mathrm{IR}$ & 1.0 \\
Body weight $(\mathrm{kg})$ & $\mathrm{BW}$ & 56.8 \\
Average time for carcinogen $(\mathrm{d})$ & $\mathrm{AT}_{\mathrm{ca}}$ & 25,550 \\
Average time for non-carcinogen $(\mathrm{d})$ & $\mathrm{AT}_{\mathrm{nc}}$ & 10,950 \\
Concentration of trace element $(\mathrm{ug} / \mathrm{L})$ & $C_{\text {water }}$ & - \\
\hline
\end{tabular}

Table 2 Values of RfD and SF

\begin{tabular}{lll}
\hline Trace element & $\begin{array}{l}\text { RfD }(\mu \mathrm{g} /(\mathrm{kg} \\
\mathrm{d})\end{array}$ & $\mathrm{SF}$ \\
\hline $\mathrm{Cr}$ & 3 & 0.5 \\
$\mathrm{Mn}$ & 140 & - \\
$\mathrm{Ni}$ & 20 & - \\
$\mathrm{Cu}$ & 40 & - \\
$\mathrm{Zn}$ & 300 & - \\
$\mathrm{Sr}$ & 600 & - \\
$\mathrm{Cd}$ & 0.5 & 0.38 \\
$\mathrm{~Pb}$ & 3.6 & - \\
\hline
\end{tabular}

According to IRIS, both $\mathrm{Cr}$ and $\mathrm{Cd}$ are regarded as carcinogens, and all detected trace elements have noncarcinogenic risks. A carcinogenic risk value below $1 \times 10^{-6}$ is considered as the acceptable level.

\subsection{Monte Carlo simulation}

The traditional deterministic risk assessment method only involves the application of simple formula, without considering the random variation of concentrations (Qiu and Gui 2019). This study introduced a Monte Carlo simulation, which works well at modeling the probability of different outcomes that previously were difficult to predict because of the influence of random variables. This method was applied in the human health risk assessment, to better understand the impact of risk, and to reduce the randomness and uncertainty in prediction. Furthermore, a followup sensitivity analysis was also carried out to identify the most influential variables (Hossain and Patra 2020). The Monte Carlo simulation customizes a series of random values for each input variable, and runs the model using 10,000 iterations to obtain the probability distributions with different confidence levels (1\%-99\%), implemented in Crystal Ball software. The fitted probability distributions and AD statistic values of the detected trace elements in SG and MG are listed in Table 3.

\section{Results and discussion}

\subsection{Pollution of groundwater by trace elements}

The results of the trace elements' analysis are shown in Table 4. The highest contents found were those of $\mathrm{Sr}$ and $\mathrm{Mn}$, while the lowest were those of $\mathrm{Cd}$ and $\mathrm{Pb}$. According to the standard for groundwater quality of China $(\mathrm{GB} / \mathrm{T}$ 14848-2017), and drinking water standards of the World Health Organization (WHO) (WHO 2011), the concentrations of $\mathrm{Sr}$ and $\mathrm{Mn}$ found here were higher than their 
Table 3 Fitted distribution of elements concentration for groundwater and goodness of fit (GoF) test outcome

\begin{tabular}{|c|c|c|c|c|}
\hline \multirow[t]{2}{*}{ Parameter } & \multicolumn{2}{|l|}{ SG (shallow groundwater) } & \multicolumn{2}{|l|}{ MG (mid-layer groundwater) } \\
\hline & Distribution (fitted parameters) & $\begin{array}{l}\text { Anderson- } \\
\text { Darling test }\end{array}$ & Distribution (fitted parameters) & $\begin{array}{l}\text { Anderson- } \\
\text { Darling test }\end{array}$ \\
\hline $\mathrm{Cr}$ & Log-normal $($ meanlog $=0.05$, sdlog $=0.07)$ & 1.4747 & Log-normal $($ meanlog $=0.22$, sdlog $=0,16)$ & 0.2684 \\
\hline $\mathrm{Mn}$ & Log-normal $($ meanlog $=274.85$, sdlog $=4033.96)$ & 0.7609 & Weibull $($ scale $=209.55$, shape $=3.04658)$ & 0.2021 \\
\hline $\mathrm{Ni}$ & Log-normal $($ meanlog $=0.22$, sdlog $=0.38)$ & 0.2739 & Log-normal $($ meanlog $=1.27$, sdlog $=0.83)$ & 0.2808 \\
\hline $\mathrm{Cu}$ & Log-normal $($ meanlog $=0.08$, sdlog $=0.09)$ & 0.3374 & Log-normal $($ meanlog $=0.16$, sdlog $=1.10)$ & 0.3399 \\
\hline $\mathrm{Zn}$ & Logistic $($ mean $=0.12$, scale $=0.30)$ & 6.5937 & Log-normal $($ meanlog $=13.65$, sdlog $=61.67)$ & 0.4514 \\
\hline $\mathrm{Sr}$ & Log-normal $($ meanlog $=1516.37$, sdlog $=690)$ & 0.1304 & Log-normal $($ meanlog $=1338.23$, sdlog $=671)$ & 0.1826 \\
\hline $\mathrm{Cd}$ & Gamma $($ scale $=0.01$, shape $=1.77119)$ & 0.4930 & Log-normal (meanlog $=0.02$, sdlog $=0.02)$ & 0.3995 \\
\hline $\mathrm{Pb}$ & Log-normal $($ meanlog $=0.01$, sdlog $=0.01)$ & 0.7460 & Log-normal $($ meanlog $=0.01$, sdlog $=0.01)$ & 0.5050 \\
\hline
\end{tabular}

Table 4 Composition of trace elements in the two groundwater types

\begin{tabular}{|c|c|c|c|c|c|c|c|c|c|c|}
\hline \multirow[t]{2}{*}{ Item } & \multicolumn{5}{|c|}{ SG (shallow groundwater) } & \multicolumn{5}{|c|}{ MG (mid-layer groundwater) } \\
\hline & Min & Max & Mean $^{\mathrm{a}}$ & SD & $\mathrm{CV}(\%)$ & Min & Max & Mean $^{a}$ & SD & $\mathrm{CV}(\%)$ \\
\hline $\mathrm{Cr}$ & 0.02 & 1.54 & 0.08 & 0.27 & 319.28 & 0.02 & 0.59 & 0.21 & 0.15 & 71.11 \\
\hline $\mathrm{Mn}$ & 0.03 & 564.57 & 78.87 & 118.01 & 149.63 & 20.72 & 256.80 & 119.69 & 67.12 & 56.08 \\
\hline $\mathrm{Ni}$ & 0.01 & 0.85 & 0.20 & 0.20 & 101.81 & 0.72 & 2.28 & 1.21 & 0.46 & 38.11 \\
\hline $\mathrm{Cu}$ & 0.01 & 0.32 & 0.08 & 0.08 & 104.32 & 0.00 & 0.73 & 0.10 & 0.18 & 191.04 \\
\hline $\mathrm{Zn}$ & 0.00 & 2.30 & 0.27 & 0.63 & 230.85 & 0.13 & 37.22 & 8.07 & 9.98 & 123.73 \\
\hline $\mathrm{Cd}$ & 0.00 & 0.06 & 0.03 & 0.02 & 68.67 & 0.01 & 0.07 & 0.02 & 0.01 & 66.52 \\
\hline $\mathrm{Pb}$ & 0.00 & 0.05 & 0.01 & 0.01 & 105.76 & 0.00 & 0.05 & 0.01 & 0.01 & 75.69 \\
\hline
\end{tabular}

${ }^{\mathrm{a}}$ Units are ug/L

permissible concentration, while the contents of other trace elements occurred at relatively low levels. Therefore, it can be inferred that the groundwater was polluted with $\mathrm{Sr}$ and Mn to different degrees.

According to the statistics, $28.13 \%$ of SG samples had an Mn content above the standard values set by China and WHO, whereas $61.11 \%$ of the MG samples' Mn content exceeded the standard values. Related research findings on shallow water in the study area reported that $41.18 \%$ of the Mn samples exceeded the standard values (Qiu et al. 2018). The high concentration of $\mathrm{Mn}$ is likely due to the regional stratigraphic lithology. The loose layer of the Sulin coalmining district is mainly composed of clay, silt-clay, and silt-loam. In these types of soil, the content of clay minerals (such as montmorillonite and illite) are relatively high, which enables them to adsorb Mn. Water-rock interactions can augment the Mn content of groundwater (Zhang et al. 2012). Table 4 also shows that the Sr content of both SG and MG samples were above the minimum reporting level (MRL) of $0.3 \mu \mathrm{g} / \mathrm{L}$. Nearly half $(46.88 \%)$ of the SG samples had an $\mathrm{Sr}$ content above the health reference level
(HRL) of $1500 \mu \mathrm{g} / \mathrm{L}$ (USEPA 2015), whereas $22.22 \%$ of MG samples' $\mathrm{Sr}$ contents surpassed the HRL. These findings are in line with a previous study (Fang et al. 2020). There are two sources of Sr: one is the primitive $\mathrm{Sr}$ existing in the formation of the earth, and the other is the ${ }^{87} \mathrm{Sr}$ of radioactive origin. The loose layer in the Sulin mining area is composed of weathered products of silicate, carbonate, and sulfate rocks, all of which are always enriched with $\mathrm{Sr}$, and this $\mathrm{Sr}$ is able to enter SG and MG via water-rock interactions (Gui and Chen 2016).

\subsection{Human health risk assessment}

The health risks caused by each analyzed trace element were calculated using Eqs. (1)-(4). In the probabilistic risk analysis model, outliers could drive deviations in the maximum and minimum model values; so, it was suggested that 5 th percentile $(5 \%)$ and 95 th percentile $(95 \%)$ be viewed respectively as the low- and high-end estimates for the probabilistic risk calculations (Saha et al. 2017). 

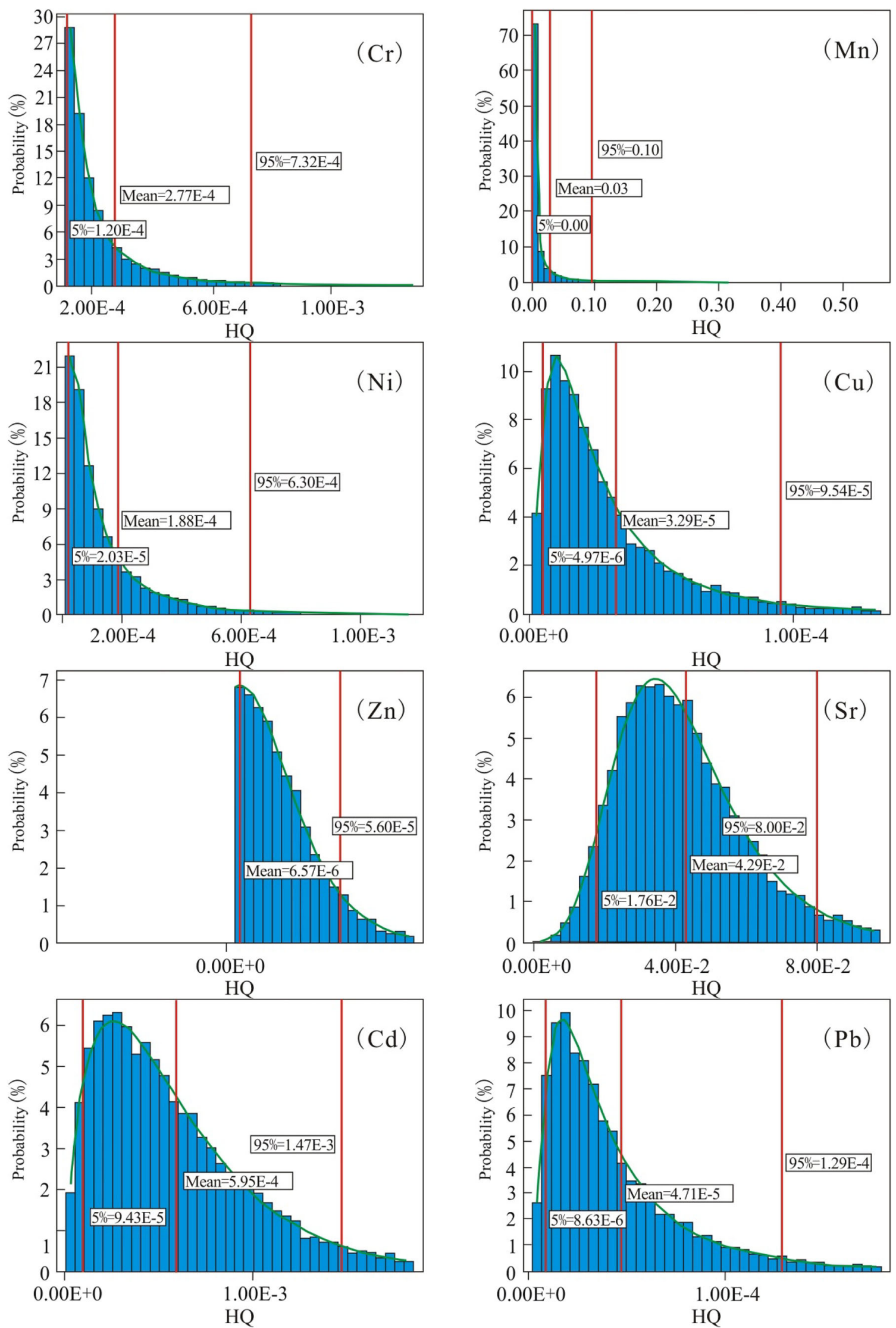
4Fig. 2 Probabilistic estimates of HQ for SG

\subsubsection{Hazard quotient $(H Q)$}

The HQs of all the analyzed trace elements for adults through ingestion exposure were calculated using Monte Carlo simulations. At 95\% confidence level, probabilistic estimates of HQ for SG and MG via ingestion by an adult are graphically displayed in Figs. 2 and 3, respectively.

Those clearly show the estimated 5\%, mean and $95 \%$ values of the HQs related to each analyzed trace element through SG and MG by oral ingestion, respectively. The mean health risk values of eight trace elements in SG were ranked as follows: $\mathrm{Sr}>\mathrm{Mn}>\mathrm{Cd}>\mathrm{Cr}>\mathrm{Ni}>\mathrm{Pb}>$ $\mathrm{Cu}>\mathrm{Zn}$; those in $\mathrm{MG}$ were ranked thus: $\mathrm{Sr}>\mathrm{Mn}>$ $\mathrm{Cr}>\mathrm{Ni}>\mathrm{Zn}>\mathrm{Cd}>\mathrm{Cu}>\mathrm{Pb}$. In both cases, the highest risk values posed by trace element were observed for $\mathrm{Sr}$. Combined with the regional stratigraphy, the loose layer of this area is composed of weathered products of silicate, carbonate, and sulfate rocks, always enriched with $\mathrm{Sr}$ (Gui and Chen 2016), which resulted in the high pollution risk level caused by $\mathrm{Sr}$.

Generally, an HQ $>1$ would indicate that an adverse effect caused by that trace element on human health is likely to occur. Whether it is SG or MG, the mean and 95th percentile HQ values of eight trace elements were within the line of the benchmark value of 1, as shown in Figs. 2 and 3. Therefore, non-carcinogenic health risks due to $\mathrm{Cr}$, $\mathrm{Mn}, \mathrm{Ni}, \mathrm{Cu}, \mathrm{Zn}, \mathrm{Sr}, \mathrm{Cd}$, and $\mathrm{Pb}$ exposure were characterized as insignificant.

\subsubsection{Hazard index $(H I)$}

Probabilistic estimates of HI for the detected trace elements in SG and MG through exposure to ingestion appear in Fig. 4. For both SG and MG ingestion, the mean and 95th percentile values of their HIs were also well below the safety level of 1 , suggesting no possible health risk posed to the local populace in terms of groundwater ingestion in the Sulin coal-mining district. For the exposed population to $\mathrm{SG}$ and MG, Sr contributed the most risk; hence, special attention and investigation should be paid to this trace element.

\subsubsection{Carcinogenic risk}

The carcinogenic risk to adults from ingestion exposure to $\mathrm{SG}$ and $\mathrm{MG}$ were calculated for $\mathrm{Cr}$ and $\mathrm{Cd}$ using Monte Carlo simulations. At the $95 \%$ confidence level, the probability distributions of health risk value caused by carcinogens are graphically displayed in Figs. 5 and 6. These results suggested that in the study area, those people who consumed SG contaminated with $\mathrm{Cr}$ and $\mathrm{Cd}$ had carcinogenic risk values varying from $7.70 \times 10^{-8}$ to $4.78 \times 10^{-7}$, and $7.61 \times 10^{-8}$ to $1.20 \times 10^{-7}$, respectively; for $\mathrm{MG}$, the corresponding values varied from $1.63 \times 10^{-7}$ to $1.89 \times 10^{-6}, \quad 2.90 \times 10^{-8}$ to $1.27 \times 10^{-7}$, respectively. It is noted that potential carcinogenic health risk values for $\mathrm{Cr}$ and $\mathrm{Cd}$ from $\mathrm{SG}$ were well below $1 \times 10^{-6}$, while for $\mathrm{MG}$, the values of $\mathrm{Cr}$ exceeded the safety level of $1 \times 10^{-6}$. Therefore, this study identified $\mathrm{Cr}$ as a priority pollutant. Because the study area is within a coal mining area, previous studies have shown that such high contents of $\mathrm{Cr}$ were mainly caused by diffuse coal dust infiltration during the process of coal mining (Yang and Xiong 2018). Therefore, the high pollution risk level caused by $\mathrm{Cr}$ might originate from long-term coal mining activities. This interpretation and view agrees with published articles on investigation by Fang et al. (2020) and Lin et al. (2017).

Considering the two trace elements $\mathrm{Cr}$ and $\mathrm{Cd}$, the total cancer risks through ingestion exposure to $\mathrm{SG}$ and $\mathrm{MG}$ were estimated and displayed in Figs. 7 and 8. Probabilistic estimates for the total cancer risk values for SG ranged from $9.90 \times 10^{-8}$ to $5.42 \times 10^{-7}$, with a mean value of $2.29 \times 10^{-7}$, while for MG they varied from $2.09 \times 10^{-7}$ to $1.93 \times 10^{-6}$, with a mean value of $8.41 \times 10^{-7}$. Although the 95th percentile total cancer risk values for MG exceeded $1 \times 10^{-6}$, the probabilistic mean total cancer risk was below the limit of $1 \times 10^{-6}$. According to the derived cumulative probability distribution curves (Figs. 7b, 8b), the probabilistic simulation showed that $0 \%$ of total cancer risk values for SG and $29.39 \%$ of total cancer risk values for MG were higher than $1 \times 10^{-6}$; this implied that MG might have low level of contamination and the local population can safely drink that groundwater. For the exposed population to $\mathrm{SG}$ and $\mathrm{MG}, \mathrm{Cr}$ contributed more the total cancer risks than did $\mathrm{Cd}$, therefore we should pay more attention to chromium pollution in the local groundwater.

\subsubsection{Sensitivity analysis}

With the help of Oracle Crystal Ball software, a sensitivity analysis (SA) was used to determine the most significant input variables that influenced the results of our risk estimation (Li et al. 2018). Figure 9 displays the results of the $\mathrm{SA}$ of non-carcinogenic health risks, for which $\mathrm{Sr}$ and $\mathrm{Mn}$ were evidently the two most influential variables for SG and MG. The SA results for carcinogenic health risks appear in Fig. 10, which show that $\mathrm{Cr}$ was the main variable affecting the total cancer risk. Although Monte Carlo simulation can quantify the uncertainty of human health risk, not all uncertainties in health risk assessment could be 

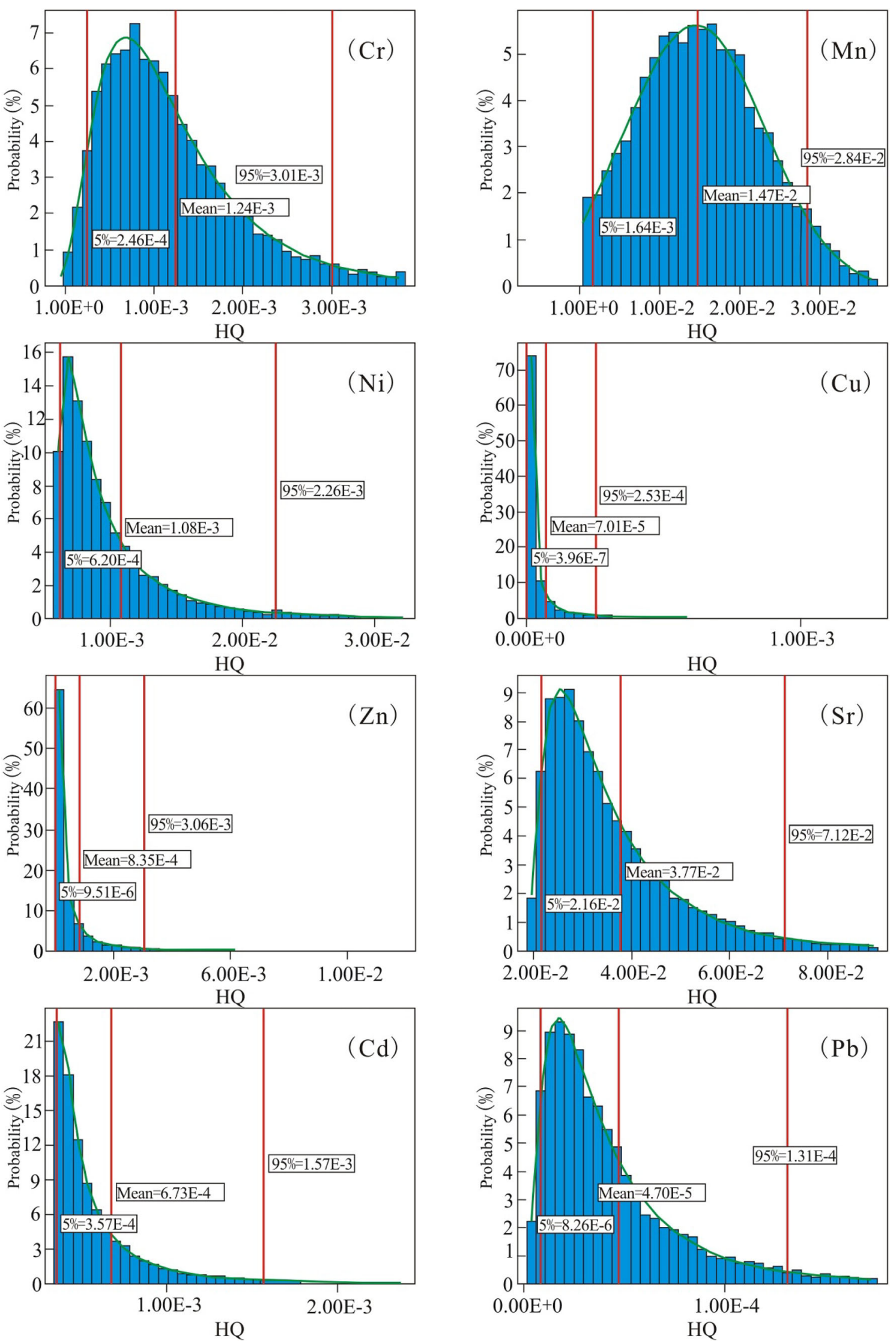
4Fig. 3 Probabilistic estimates of HQ for MG

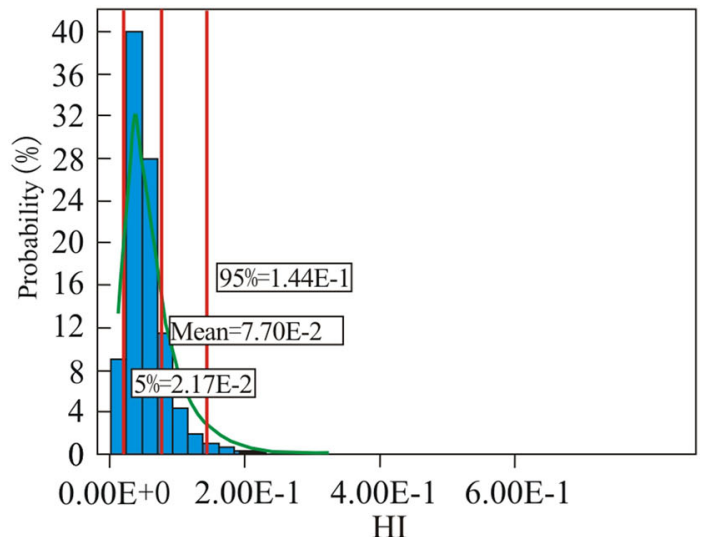

(a)

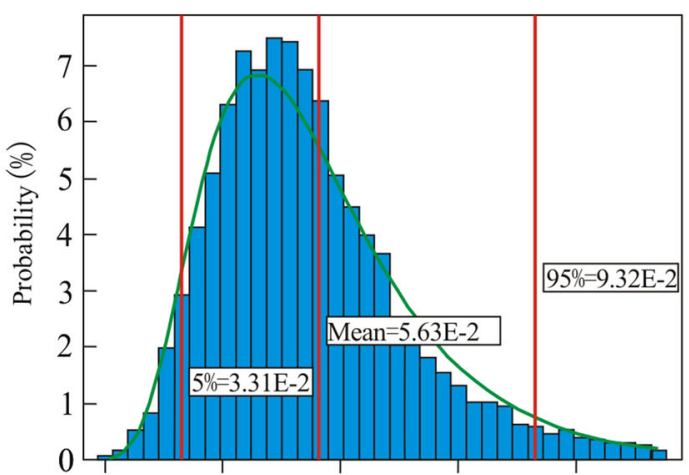

2.00E-2 4.00E-2 6.00E-2 8.00E-2 1.00E-1

$\mathrm{HI}$

(b)

Fig. 4 Probabilistic estimates of HI: a $\mathrm{HI}$ for SG, b $\mathrm{HI}$ for MG

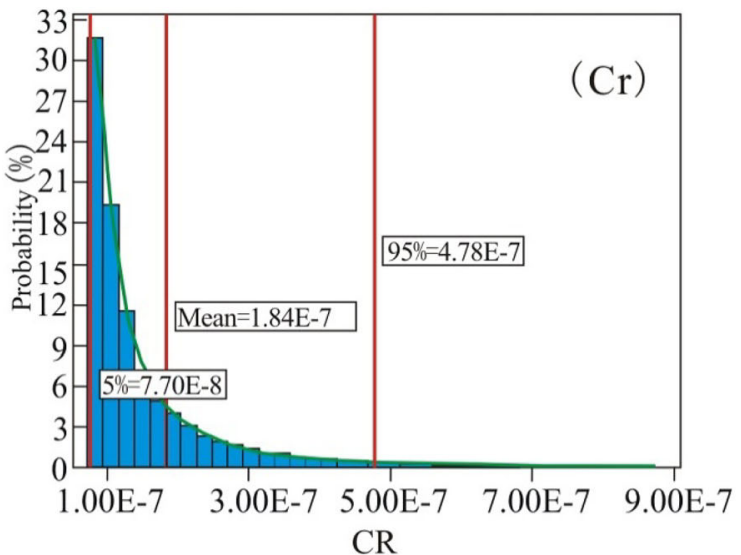

accounted for. Accordingly, the focus of future research work should be on reducing the uncertainty of risk.

\section{Conclusions}

This research collected 52 groundwater samples and investigated their eight trace elements' concentrations, along with their health risks. The results revealed that $28.13 \%$ of SG samples and $61.11 \%$ of MG samples had Mn contents above the standard guideline values prescribed by WHO and China, while $46.88 \%$ of SG samples and $22.22 \%$ of MG samples had an Sr content higher than the HRL. The results of the health risk assessment suggested that the mean and 95th percentile values of HQ and HI associated with each target trace element, in SG and MG, through exposure to ingestion for adult, were all within the limit of 1. Moreover, probabilistic-estimated 95th percentile values of total cancer risk for MG exceeded $1 \times 10^{-6}$, but the mean total cancer risk values for $\mathrm{SG}$ and $\mathrm{MG}$ were below the benchmark. We may conclude that the non-carcinogenic and carcinogenic risks from SG and $\mathrm{MG}$ are not serious in the studied region. The sensitivity analysis results indicated the $\mathrm{Cr}$ and $\mathrm{Sr}$ contents were the most influential factors affecting the probabilistic risk estimation model outcome.

Although Monte Carlo simulations can quantify the uncertainty of human health risk, other uncertainties persist in health risk assessment. Therefore, a more accurate and precise evaluation ought to be carried out by considering additional factors. Despite those uncertainties, the research findings here are useful for formulating a management plan for proper utilization of groundwater resource in the studied area. Moreover, the methods and techniques used in

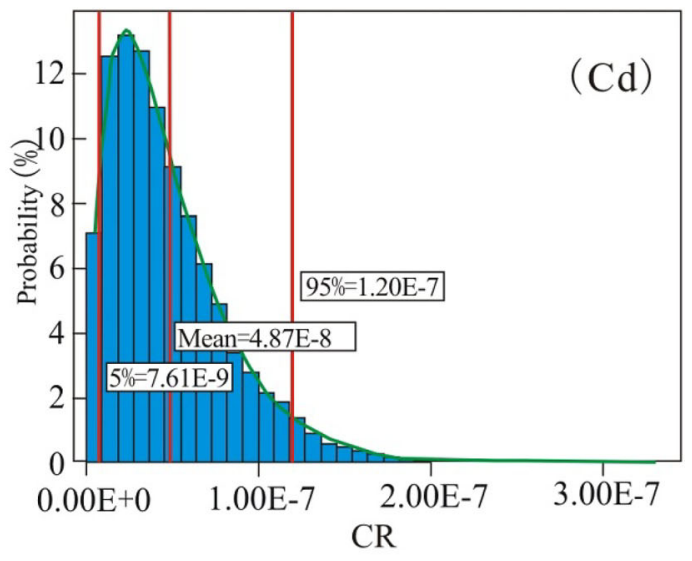

Fig. 5 Probabilistic estimates of cancer risk for SG through ingestion by adults 

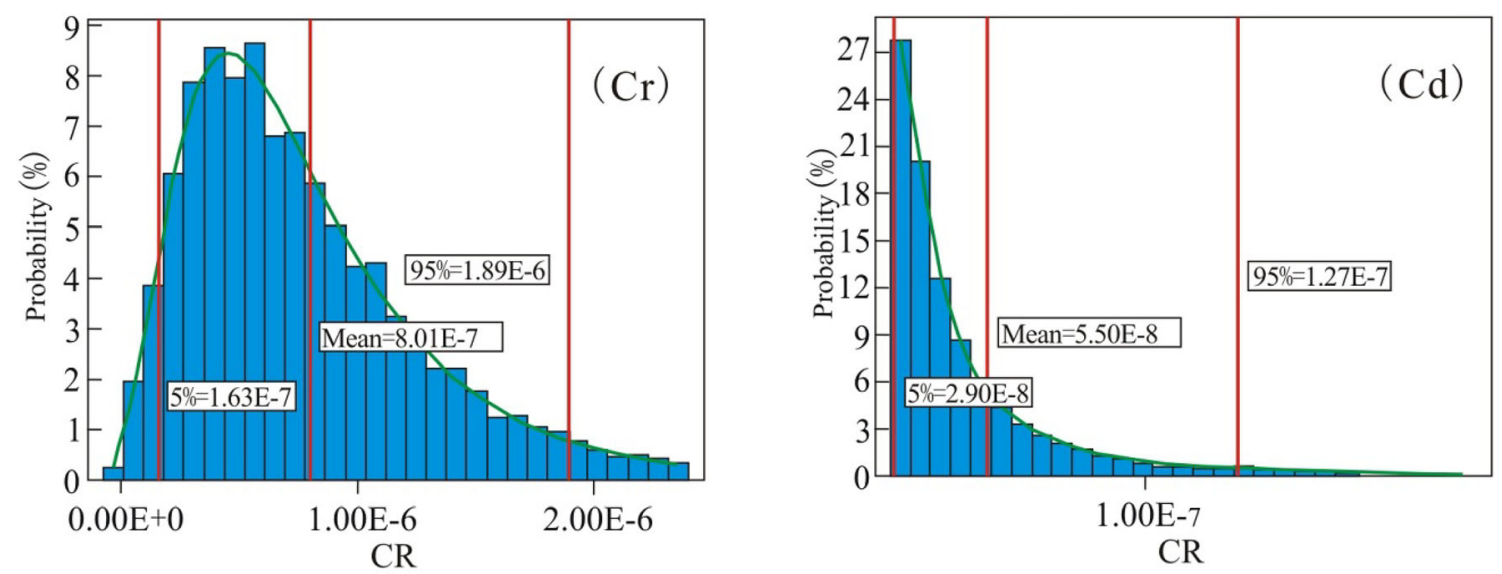

Fig. 6 Probabilistic estimates of cancer risk for MG through ingestion by adults

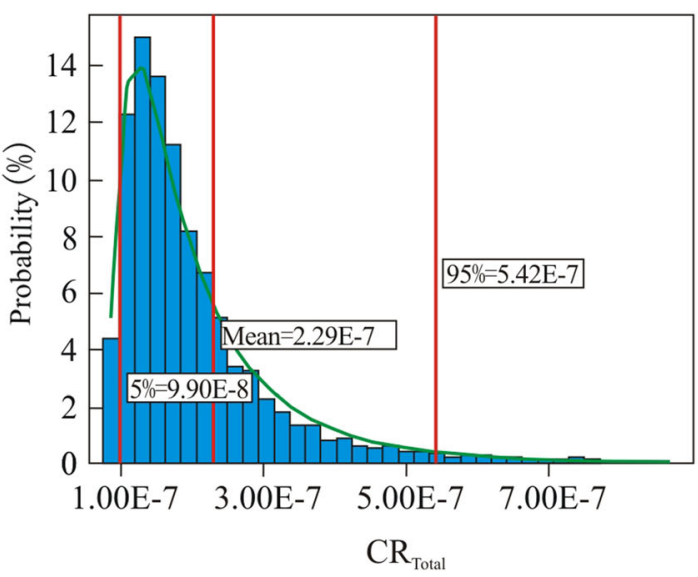

(a)

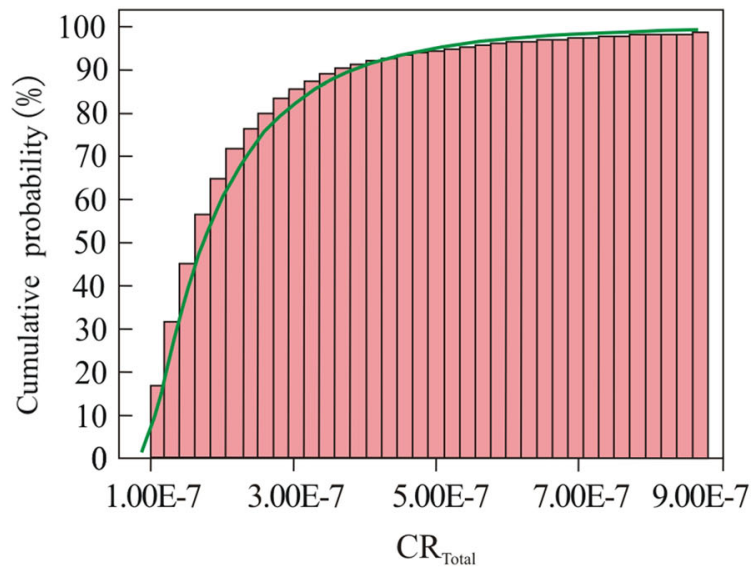

(b)

Fig. 7 Probability distribution: a Probability distribution of total cancer risks for SG. b Cumulative probability distribution of total cancer risks for $\mathrm{SG}$

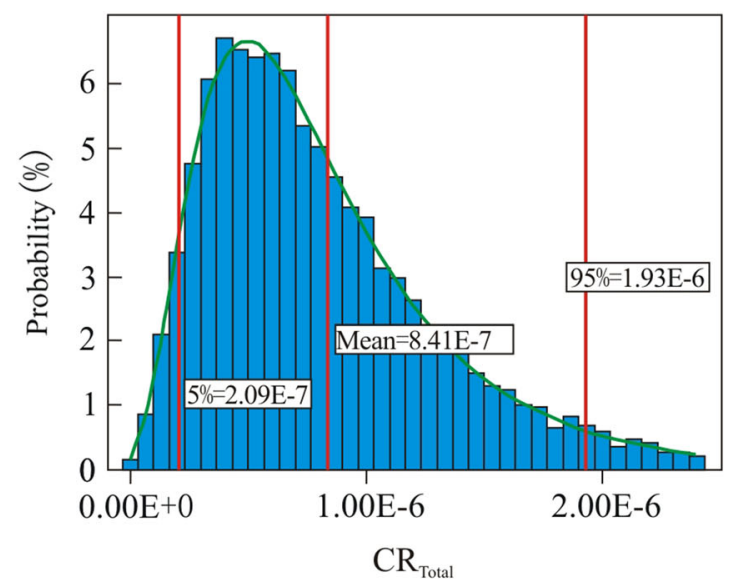

(a)

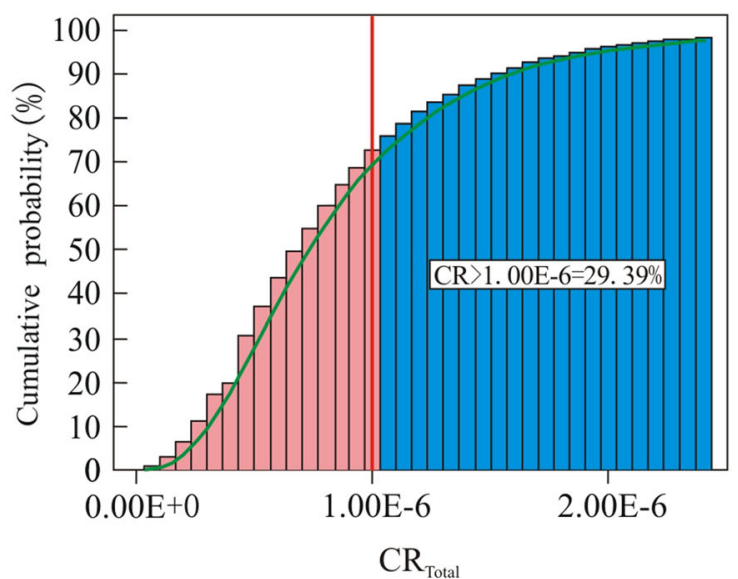

(b)

Fig. 8 Probability distributions: a Probability distribution of total cancer risks for MG. b Cumulative probability distribution of total cancer risks for MG 


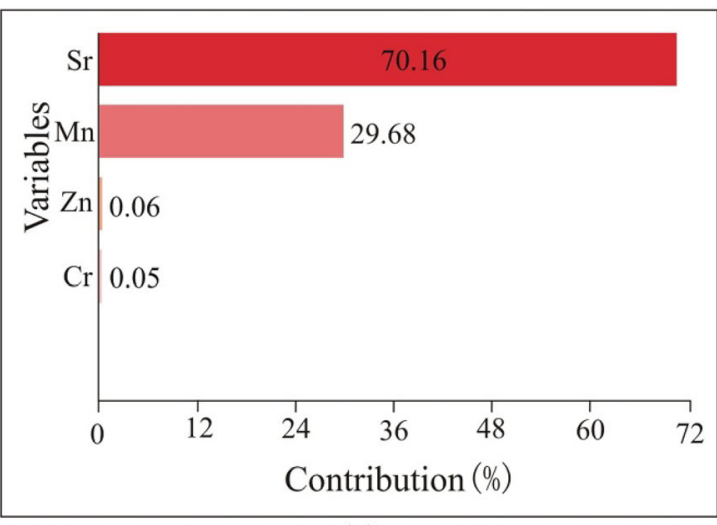

(a)

Fig. 9 The SA results of total non-carcinogenic risks: a SG, b MG

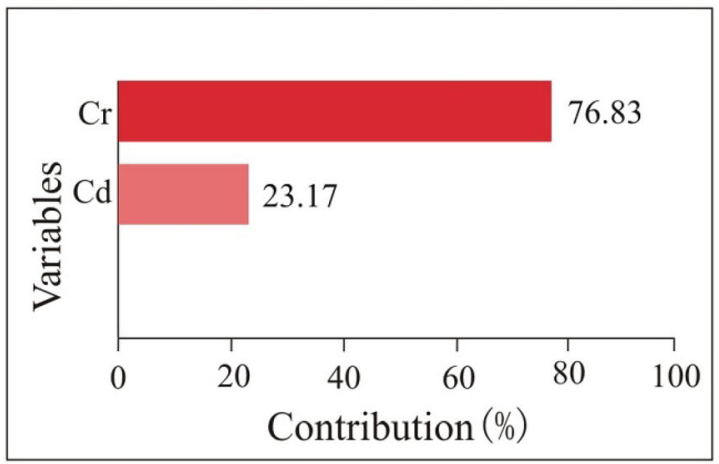

(a)

Fig. 10 The SA results of total carcinogenic risks: a SG, b MG

this study are helpful for exploring the risk management of groundwater toxicity for human health in other regions.

Acknowledgements The authors sincerely thank the manuscript handling editors and reviewers for their insightful comments that helped to greatly improve this paper. This study was financially supported by the National Natural Science Foundation of China (41773100); the Natural Science Foundation of Anhui Province (2008085QD192); the Key Project of Excellent Talents support program in colleges and universities (gxyqZD2020048); a doctoral research initiation fund Project (2020BS010); a postdoctoral research initiation fund project (2021BSH001); the fourth batch of excellent academic and technical backbone Projects of Suzhou University (2020XJGG02); the Research Project of Wanbei Coal-Electricity Group Co. Ltd. (2020); and the Project for research activities of academic and technological leaders of Anhui Province (2020D239).

Open Access This article is licensed under a Creative Commons Attribution 4.0 International License, which permits use, sharing, adaptation, distribution and reproduction in any medium or format, as long as you give appropriate credit to the original author(s) and the source, provide a link to the Creative Commons licence, and indicate if changes were made. The images or other third party material in this article are included in the article's Creative Commons licence, unless indicated otherwise in a credit line to the material. If material is not included in the article's Creative Commons licence and your intended use is not permitted by statutory regulation or exceeds the permitted use, you will need to obtain permission directly from the copyright

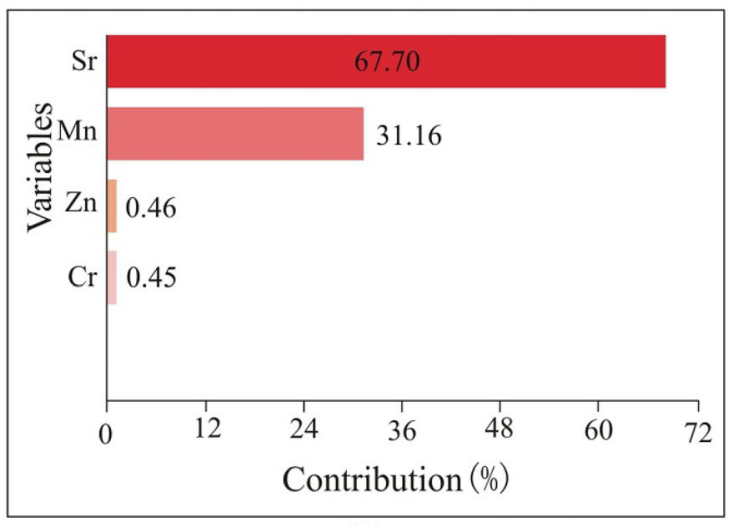

(b)

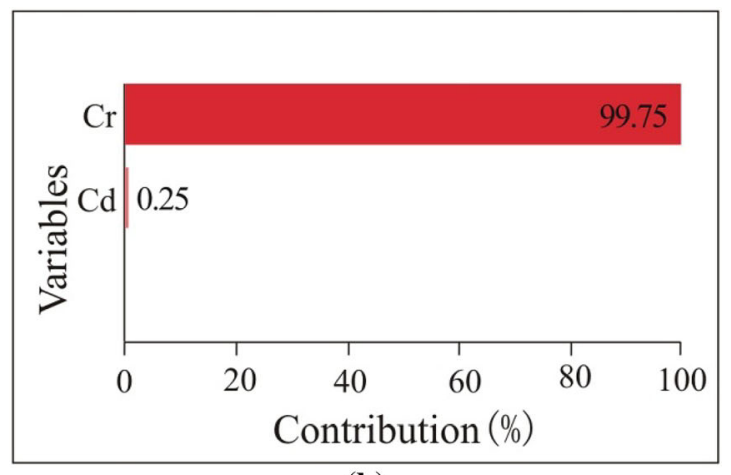

(b)

holder. To view a copy of this licence, visit http://creativecommons. org/licenses/by/4.0/.

\section{References}

Adimalla N, Wu J (2019) Groundwater quality and associated health risks in a semi-arid region of south India: Implication to sustainable groundwater management. Hum Ecol Risk Assess 25(1-2):191-216

Al osman M, Yang F, Massey IY (2019) Exposure routes and health effects of heavy metals on children. Biometals 32:563-573

Bodrud-Doza M, Islam SMD-U, Hasan MT, Alam F, Haque MM, Rakib MA, Asad MA, Rahman MA (2019) Groundwater pollution by trace metals and human health risk assessment in central west part of Bangladesh. Groundw Sustain Dev 9:100219

Cai LM, Wang QS, Luo J, Chen LG, Zhu RL, Wang S, Tang CH (2019) Heavy metal contamination and health risk assessment for children near a large $\mathrm{Cu}$-smelter in central China. Sci Total Environ 650:725-733

Chen X, Zheng LG, Jiang YL, Jiang CL (2021) Transformation of minerals at the boundary of magma-coal contact zone: case study from Wolonghu Coal Mine, Huaibei Coalfield, China. Int J Coal Sci Technol 8(1):168-175

Fang HX, Gui HR, Yu H, Li J, Wang MC, Jiang YQ, Wang CL (2020) Chen $C$ (2020) Characteristics and source identification of heavy metals in abandoned coal-mining soil: a case study of Zhuxianzhuang coal mine in Huaibei coalfield (Anhui, China). 
Hum Ecol Risk Assess. https://doi.org/10.1080/10807039.2020. 1750346

Gui HR, Chen S (2016) Isotopic geochemical characteristics of groundwater and its geological significance in Sunan mining area. Earth Sci Front 23(3):133-139

Hossain M, Patra PK (2020) Conramination zoning and health risk assessment of trace elements in groundwater through geostatistical modelling. Ecotoxicol Environ Saf 189:110038

Hu GQ, Liu GJ, Wu D, Zhang WY, Fu B (2021) Method for evaluation of the cleanliness grade of coal resources in the Huainan Coalfield, Anhui, China: a case study. Int J Coal Sci Technol. https://doi.org/10.1007/s40789-020-00400-6

Jiang YQ, Gui HR, Yu H, Wang MC, Fang HX, Wang CL, Chen C, Zhang YR, Huang YH (2020) Hydrochemical characteristics and water quality evaluation of rivers in different regions of cities: a case study of Suzhou city in Northern Anhui Province, China. Water 12(4):1-22

Kaur L, Rishi MS, Siddiqui AU (2019) Deterministic and probabilistic health risk assessment techniques to evaluate non-carcinogenic human health risk (NHHR) due to fluoride and nitrate in groundwater of Panipat, Haryana, India. Environ Pollut 269:113711

Li FW, Zhu JZ, Deng XY, Zhao Y, Li SF (2018) Assessment and uncertainty analysis of groundwater risk. Environ Res 160:140-151

Lin ML, Gui HR, Wang Y, Peng WH (2017) Pollution characteristics, source apportionment, and health risk of heavy metals in street dust of Suzhou, China. Environ Sci Pollut Res 24:1987-1998

Long J, Luo KL (2020) Elements in surface and well water from the central North China Plain: enrichment patterns, origins, and health risk assessment. Environ Pollut 258:113725

Nurtazin S, Pureppke S, Ospan T, Mukhitdinov A, Elebessov T (2020) Quality of drinking water in the Balkhash District of Kazakhstan's Almaty region. Water 12:392

Qiu HL, Gui HR (2019) Heavy metals contamination in shallow groundwater of a coal-mining district and a probabilistic assessment of its human health risk. Hum Ecol Risk Assess 25(3):548-563

Qiu HL, Gui HR, Song QX (2018) Human health risk assessment of trace elements in shallow groundwater of the Linhuan coalmining district, Northern Anhui Province, China. Hum Ecol Risk Assess 24(5):1342-1351

Qiu HL, Gui HR, Cui L, Pan ZG, Lu B (2019) Hydrogeochemical characteristics and water quality assessment of shallow groundwater: a case study from Linhuan coal-mining district in northern Anhui Province, China. Water Sci Technol Water Supply 19(5):1572-1578
Saha N, Rahman MS, Ahmed MB, Zhou J, Ngo HH, Gao WS (2017) Industrial metal pollution in water and probabilistic assessment of human health risk. J Environ Manag 185:70-78

US-EPA (US Environmental Protection Agency) (2015) The Third Unregulated Contaminant Monitoring Rule (UCMR 3): Data Summary. EPA 815-S-15-002. Washington, D.C

Wang MC, Gui HR, Hu RJ, Zhao H, Li J, Yu H, Fang H (2019) Hydrogeochemical characteristics and water quality evaluation of carboniferous Taiyuan formation limestone water in Sulin Mining area in Northern Anhui, China. Int J Environ Res Public Health 16(4):2152

WHO (Word Health Organization) (2011) Guidelines for drinking water quality, 4 th edn. Geneva

Xiao J, Wang LQ, Deng L, Jin ZD (2019) Characteristics, sources, water quality and health risk assessment of trace elements in river water and well water in the Chinese Loess Plateau. Sci Total Environ 650(2):2004-2012

Yang L, Xiong HG (2018) The soil heavy metal pollution analysis and source apportionment in Zhundong mining area. China Min Mag 27(9):121-126

Yang S, Yang Q, Ma H, Liang J, Niu CW, Martin JD (2018) Health risk assessment of phreatic water based on triangular fuzzy theory in Yinchuan plain. Ecotoxicol Environ Saf 164:732-738

Yu H, Gui HR, Jiang YQ, Li ZC, Wang MC, Fang HX, Wang CL, Chen C, Qiu HL, Zhang YR (2020a) Characteristics of dissolved organic matter content in urban rivers under different environmental impact zones: a case study of China's Tuo River. Pol J Environ Stud 29(5):1-10

Yu H, Gui HR, Zhao HH, Wang MC, Li J, Fang HX, Jiang YQ, Zhang YR (2020b) Hydrochemical characteristics and water quality evaluation of shallow groundwater in Suxian mining area, Huaibei coalfield, China. Int J Coal Sci Technol 7(4):825-835

Zhang B, Song X, Zhang Y, Han DM, Tang CY, Yu YL, Ma Y (2012) Hydrochemical characteristics and water quality assessment of surface water and groundwater in Songnen plain, Northeast China. China Water Res 46(8):2737-2748

Zhang L, Huang D, Yang J, Wei X, Qin J, Ou S, Zou Y (2017) Probabilistic risk assessment of Chinese residents' exposure to fluoride in improved drinking water in endemic fluorosis areas. Environ Pollut 222:118-125

Zhang H, Zhou X, Wang LB, Wang WD, Xu JL (2018) Concentrations and potential health risks of strontium in drinking water from Xi'an, Northern China. Ecotoxicol Environ Saf $164: 181-188$ 